\title{
Novel Portable Laser Ablation Micro-Sampling in Cultural Heritage
}

\author{
Alice Knaf ${ }^{1}$, Pablo Londero² ${ }^{2}$ James Nikkel ${ }^{3}$, Richard Hark ${ }^{1}$ and Aniko Bezur ${ }^{1}$ \\ ${ }^{1}$ Yale University, Institute for the Preservation of Cultural Heritage, United States, ${ }^{2}$ Louvre Abu Dhabi, \\ Research Laboratory, United States, ${ }^{3}$ Yale University, Advanced Prototyping Centre in Wright Lab, United \\ States
}

This paper describes the evaluation of a prototype semi-portable UV laser ablation (LA) sampling device for provenance and composition studies of transparent and translucent materials such as clear glass, porcelain, feldspar minerals, teeth, etc. encountered in cultural heritage and forensics. Preliminary geochemical analysis (major/trace elements and strontium/lead isotope composition) of two NIST glasses (SRM 610 and 614) and two Corning glasses (A and leaded D) was carried out to validate the system and assess the reproducibility and precision of the data.

Chemical fingerprinting of materials encountered in cultural heritage can inform us about how, when, and where objects were made, and may help reconstruct material pathways from sources to artifacts. Over the last two decades, major- and trace elemental, as well as isotopic composition analyses have been deployed with increasing frequency in cultural heritage research [1]. The availability of portable and handheld versions of non-destructive instruments, such as X-ray fluorescence (XRF) and Raman spectrometers has allowed researchers "to take the lab to the objects" in both field contexts as well as in collection spaces, such as storage rooms and exhibition galleries. When it comes to bulk analyses, both techniques are hindered by the presence of surface alterations and coatings. Portable and handheld laser-induced breakdown spectrometers (LIBS) offer a minimally-invasive solution to surface and bulk analysis through the progressive ablation of an artifact's surface, however, accurate quantification of elements remains a challenge and isotope composition analysis is highly limited. Sample-based destructive techniques, such as inductively coupled plasma mass spectrometry (ICP-MS), remain unmatched when it comes to sensitivity, accuracy, and precision for both elemental and isotopic analyses.

In contrast to conventional sampling methods and strategies such as micro-drilling, scraping or cutting, laser ablation (LA) causes minimal damage. Solutions for adapting LA-ICP-MS to the direct analysis of large objects have been explored with varying success, but they all fall short in that they still require the transportation of collection objects offsite as in-house LA-ICP-MS capacity is rare in collections. The decoupling of LA from subsequent elemental or isotopic analysis has emerged as a viable approach for virtually invisible sample removal from objects large and small in collection contexts or in the field. The novel laser ablation tool (Fig. 1) creates ablation pits the size of human hair diameters $(50-100 \mu \mathrm{m})$ and collects the resulting sample aerosols, using a vacuum attachment, onto pre-cleaned Teflon ${ }^{\mathrm{TM}}$ filters that are transported to a clean laboratory for low blank (pg) geochemical procedures [2]. The first prototype, operating in the visible range $(\lambda 532 \mathrm{~nm})$, was built at ETH Zurich $(\mathrm{CH})$. It was validated employing a reference basalt glass and gold standard materials and subsequently applied to an ancient Chinese ceramic rod colored with Han Blue [3, 4].

Micro-sampling approaches could not have become viable without the technological improvements in analytical devices that allow accurate and precise analyses of increasingly smaller amounts of samples ( $\mu \mathrm{g}$ $\mathrm{mg}$ ). ICP-MS instrumentation sensitivity has increased by several orders of magnitude (x1000) [5] while the limits of quantification (LOQ) have decreased to a few ppt $(<3-45 \mathrm{ppt})$ for most TE [2]. Breakthroughs in thermal ionization mass spectrometry (TIMS) and Multi Collector-ICP-MS (MC-ICP-MS), and the application of double spike techniques enable the analysis of sub-nanogram amounts of important marker such as strontium, neodymium and lead. A critical limiting factor in the successful application of (ultra-) low blank geochemical techniques is the incorporation of extraneous material during sampling and chemical workup. The vacuum-assisted collection of aerosols produced by pLA under ambient conditions results in the capture 
of airborne contaminants. This may be reduced shortening ablation and collection time by improving ablation efficiency.

The four $532 \mathrm{~nm}$ pLA sampling devices currently in use - at ETH Zurich (CH), VU Amsterdam (NL), CEZA Mannheim (GER), and the Field Museum Chicago (USA) - have been successfully deployed to address a variety of research questions [6-8]. Despite these successes the analysis of translucent and transparent materials has proven to be challenging with the visible laser due to the inefficiency of the laser-matrix interactions. To overcome this the Yale Institute for the Preservation of Cultural Heritage (IPCH), is investigating the use of a portable UV laser for sample ablation. The selected laser source is a frequency-quadrupled Nd:YAG system that delivers pulses at $213 \mathrm{~nm}$ (Fig. 1). With a $532 \mathrm{~nm}$ laser it can take several minutes to ablate sufficient material from translucent samples, and slow ablation increases background from ambient air. The advantage of ablating at $213 \mathrm{~nm}$ is a strong absorption cross-section for most materials and an efficient, rapid ablation. During the shorter sampling process, typically 30 to 90 seconds, less dust from the surrounding environment will be sucked into the open ablation cell and deposited with the ablated sample aerosol onto the filter. Using a UV laser impacts portability, however, as the system needs a bigger power supply with a built-in water chiller for the laser. Another tradeoff in portability is due to the current limitation of optical fibers to transmit the UV laser pulses at the power levels needed without significant degradation. The final design for the instrument will involve an articulated arm with internal mirrors to provide a safe, closed beam path, while the current setup features a height-adjustable open beam path. In a subsequent phase the redesigned UV pLA sampling tool and optimized analytical method will be applied to a well-defined case study involving objects from Yale's collections.

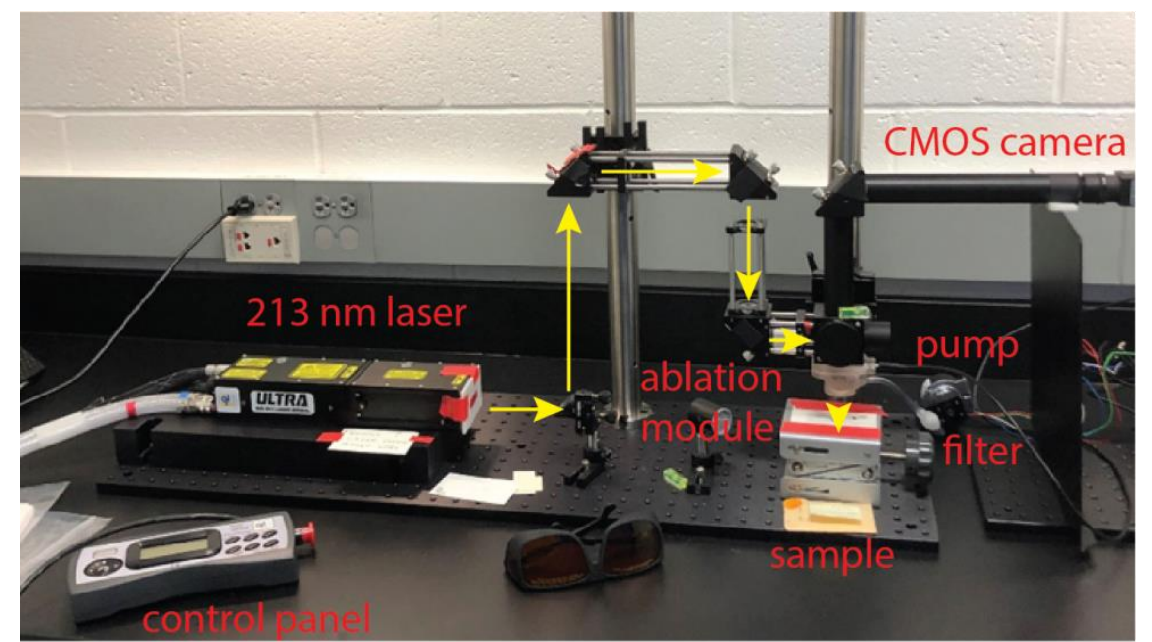

Figure 1. Portable UV LA sampling device $(5 \mathrm{~mJ}, \lambda 213 \mathrm{~nm})$ at the Yale Institute for the Preservation of Cultural Heritage. Visible are the compact pulsed Nd:YAG laser and the control panel, the beam optics that prepare the laser beam (beam path indicated in yellow), before entering the ablation head with the open ablation cell), a diaphragm micro-pump attached to a single filter holder, and a CMOS color camera. The combined power supply and chiller are not shown.

\section{References}

[1] M. D. Glascock, Compositional Analysis in Archaeology. 2016.

[2] A. C. S. Knaf, J. M. Koornneef, and G. R. Davies, "'Non-invasive" portable laser ablation sampling of art and archaeological materials with subsequent $\mathrm{Sr}-\mathrm{Nd}$ isotope analysis by TIMS using $1013 \Omega$ amplifiers," Journal of Analytical Atomic Spectrometry, 10.1039/C7JA00191F vol. 32, no. 11, pp. 2210-2216, 2017, doi: 10.1039/C7JA00191F. 
[3] R. Glaus, J. Koch, and D. Günther, "Portable Laser Ablation Sampling Device for Elemental Fingerprinting of Objects Outside the Laboratory with Laser Ablation Inductively Coupled Plasma Mass Spectrometry," Analytical Chemistry, vol. 84, no. 12, pp. 5358-5364, 2012/06/19 2012, doi: $10.1021 / \mathrm{ac} 3008626$.

[4] R. Glaus, L. Dorta, Z. Zhang, Q. Ma, H. Berke, and D. Günther, "Isotope ratio determination of objects in the field by portable laser ablation sampling and subsequent multicollector ICPMS," Journal of Analytical Atomic Spectrometry, 10.1039/C3JA30379A vol. 28, no. 6, pp. 801-809, 2013, doi: 10.1039/C3JA30379A.

[5] M. Guillong and C. A. Heinrich, "Sensitivity enhancement in laser ablation ICP-MS using small amounts of hydrogen in the carrier gas," Journal of Analytical Atomic Spectrometry, vol. 22, no. 12, pp. 14881494, 2007.

[6] M. Burger et al., "Novel sampling techniques for trace element quantification in ancient copper artifacts using laser ablation inductively coupled plasma mass spectrometry,"

Journal of Archaeological Science, vol. 82, pp. 62-71, 2017/06/01/ 2017, doi: 10.1016/j.jas.2017.04.009.

[7] A. C. S. Knaf et al., "A holistic microwear and provenance study of pre-colonial jade objects from the Virgin Islands: Unraveling mobility networks in the wider Caribbean," Journal of Archaeological Science: Reports, under review.

[8] S. Seman, L. Dussubieux, C. Cloquet, and T. Pryce, "Strontium isotope analysis in ancient glass from South Asia using portable laser ablation sampling," Archaeometry, 2020. 